\title{
Archaeology and evolution
}

\section{What happens when you clean your office}

\author{
by Denise Beaubien Bennett
}

$\mathrm{T}$ o celebrate the arrival of some new of fice furniture, the inhabitants of the Electronic Formats Unit in the Marston Science Library at the University of Florida cleaned the entire area. We were fortunate to have Student Assistant Allan, who doubles as computer geek and neatnik, on the payroll during our cleanup.

Those of us who have survived the technical revolution in libraries tend to react with bemusement when we encounter relics while cleaning our offices. But Allan is in his early $20 \mathrm{~s}$, and he reacted with wonder, amazement, and reverence as he dug through the layers of accumulated treasures.

Allan unearthed a Hypercard package, circa 1990. "I don't know what this is, but it looks pretty cool!" I explained how Apple developed the program to hyperlink discrete "cards" within a "stack," years before the Web exploded.

Next came a stack of floppy/CD mailers, made of corrugated cardboard. Allan asked if he could toss them. I said that we used them frequently back in the good old days, when we mailed floppies around and had to return outdated CD-ROMs to the publishers. He looked puzzled, and I explained that libraries subscribed to CDs for years before the jewel case was invented.

Allan's eyes filled with pity. Faculty member John added, "Yes, and the first CDs were made of wood!"
Then came the prize - a box with a DOS 3.30 manual and an accompanying 5.25" diskette. "I knew these existed, but I've never seen or touched one before!" Allan especially appreciated seeing "IBM" splashed over the manual and diskette. He knew that DOS was originally developed by Microsoft for IBM, but he was unaccustomed to seeing IBM receive the top billing. Allan mourned that he lacked access to a 5.25" floppy drive.

In addition to the DOS manual, Allan was surprised to see the number of older software packages that contained printed manuals. We explained that people did (and many still do) prefer to consult printed manuals, and also that old diskettes didn't have enough room to store manuals as well as programs.

Perhaps I should feel embarrassment over the length of time it took us to clean out the office. But I'm happy we saved the archaeological dig for Allan, who truly appreciated handling the relics and learning about the evolution of the technology from physical pieces to networked resources. He regarded the process as a history lesson.

Allan's reactions will serve to remind me of the perspective of the current generation of students. They handle CDs and floppies, but they expect all library resources to be networked and Web-based. And the next time one of your networked services crashes, spare a moment of thought for the days when we had to reload crashed programs from floppies. 


\section{Hello. My name is Andrew "Flip" Filipowski and, as Chairman}

and CEO of divine, inc., I'm pleased to be writing this message to the present, past and future clients of divine/Faxon Library Services. As most of you know, divine officially acquired RoweCom/Faxon on November 6th, 2001. In the months leading up to the acquisition and since that time, I have been privileged to work with the management and staff of the Faxon Library Services team. I want to let you know how impressed I have been with the professionalism and dedication of these colleagues and how much I have learned about the library business from them.

I am here to tell you that divine/Faxon Library Services is now backed by an organization with a substantial cash position, providing a solid financial foundation for continued growth and innovation. We at divine are committed to the continuation and enhancement of your traditional print and electronic subscription services, and we look forward to working with the experienced and knowledgeable Faxon employees that you know and respect. In addition, we bring to the table a large and talented organization dedicated to solving the information challenges of academic institutions and corporations with first-class technology and service. This combination will be hard to beat.

We recognize that the Faxon brand is a meaningful one with a long history signifying quality and service to libraries and are proud to have it continued as part of divine. By acquiring RoweCom/Faxon, divine is making a commitment to develop the most advanced content offerings in the industry for libraries and their clientele in all

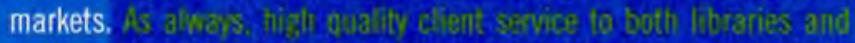
Dofiki ats mill be out gost:

I hope to have the opportunity to meet many of you in the next few months. Please do not hesitate to share your questions and ideas with the divine/Faxon staff.

Kindest regards,

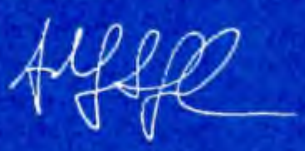

divine

Visit divine/Faxon Library Services at Booth \#3918 at ALA! 